\title{
Analytical Study of Happiness Inequality in Egypt
}

\author{
Eman Ahmed Hashem ${ }^{1}$ \\ ${ }^{1}$ Associate Professor of Economics, Ain Shams University, Cairo, Egypt \\ Correspondence: Eman Ahmed Hashem. E-mail: Emyhashem2004@yahoo.com
}

Received: September 14, 2018

Accepted: October 8, $2018 \quad$ Online Published: November 29, 2018

doi:10.5539/ass.v14n12p41

URL: https://doi.org/10.5539/ass.v14n12p41

\begin{abstract}
Based on World value survey (3 waves: 2001, 2008 \& 2012) the happiness inequality in Egypt has been enlarged. This paper illustrates the concept of happiness inequality and analysis the status of happiness inequality in Egypt. Also the paper aim to determine the main factors affecting happiness inequality in Egypt. This paper used RIF regression (Recentered influence function) to investigate the impacts of several factors like: age, educational level, employment status, gender, martial status and health status on happiness inequality in Egypt. We found that increase the population share of middle age people and increase unemployment rate can enlarge Egypt's happiness inequality. While an increase in educational level, improvement in health and having good job has a reducing impact on happiness inequality.
\end{abstract}

Keywords: happiness, income inequality, happiness inequality, education, Egypt

\section{Introduction}

Modern economists are more interested in analysing what actually matters to people: Money or happiness. In the last decade, new methods to define and measure happiness evolved, considering a broader analysis of happiness way beyond the increase in income or Gross Domestic Product (GDP). (Singh, 2014, p. 2)

Happiness has associated with all aspects of our life. Studies show that happier people have greater productivity levels. Also, the less conscientious that person will be in taking actions to preserve his life and this risk attitude affects saving and spending behaviour. (Andrew, 2009, p. 3)

When we are looking to the relationship between economic growth and happiness we can find that in general, countries with high level of GDP per capita have a higher level of happiness than countries with low GDP per capita and when looking within countries. Generally richer part of population is happier than poorer parts.

But it is not always true. If we look at Egypt; we will find that Algeria is very close to Egypt in GDP per capita but more than 50 ranks better in happiness ranking.

Also, Morocco and Philippines are countries with less GDP per capita but more than Egypt in happiness ranking. (United Nation (UN), 2016, p. 234)

So, economic growth is important but not sufficient to achieve high level of happiness. As there are other factors that affect happiness such as: education, age employment, health status and family.

If happiness provides a better measure of welfare and satisfaction than that provided by economic growth or Gross Domestic Product (GDP). So, inequality in the distribution of happiness between countries and within the country must be the focus of policymakers.

\subsection{What Is Happiness Inequality?}

Economics of happiness or happiness economics gives more attention to subjective and personal issues that was ignored in the past economics literature. Economics of happiness is a revolution in the understanding of how policymakers estimate the gains or loses from their decisions.

Happiness has association with every aspect of life. Studies show that happier people have greater productivity levels. Also, the less happy an individual is with life the less conscientious that person will be in taking actions to preserve his life and this risk attitude affects saving and spending behaviour as well. (Clark \& Senik, 2015, p. 2)

In fact, income inequality is just one dimension of inequality and can be reduced, to some degree, by income redistribution and transfer payment. As happiness provides better measurement for wellbeing than income.so, happiness inequality has caught much attention during recent years. (Yang, Kailiu, \& Zhang, 2015, p. 2) 
Unlike income inequality, the inequality of happiness cannot be directly eliminated by happiness transfer. Therefore, happiness inequality became a more challenging problem for policymaker in worldwide. (Yang, Kailiu, \& Zhang, 2015, p. 2)

Happiness inequality means how much individuals in a society differ in the enjoyment of their life. As another definition, happiness inequality measures the degree to which people in a country differ in their happiness levels or subjective well being.

\subsection{Happiness Measurements}

Happiness is a multidimensional and subjective matter so reaching to one definition and working it out is so difficult as it contains subjective issues.

The different measurement of happiness reflects the fact that happiness has no unified definition as happiness is a very personal matter and subjective.

\subsection{Different Measures of Happiness}

a) Happy Planet Index (HPI):

The Happy Planet Index consists of four issues to show how efficiently people in different countries are using environmental resources to reach long and happy lives.

- Life expectancy: which mean the average number of years an individual is expected to live in a given country.

- $\quad$ life satisfaction: how individuals satisfied with their life, put a number on a scale from 0 to 10 .

- Inequality of outcomes: which mean the inequalities between people live in the same country in both their feeling of happiness and their long and healthy life

- Ecological footprint (environmental damage): which mean the average impact on environment that each individual has in his country.

Theses 4 factors are brought together to calculate Happy Planet Index (HPI)

$$
\mathrm{HPI}=\frac{\text { well being } * \text { life expectancy } * \text { Inequality of outcomes }}{\text { Ecological footprint }}
$$

Scores range from 0 to 100.0 mean worst performance while 100 mean best performance.

b) Bhutan's Gross National Happiness:

Bhutan's Gross National Happiness Index consider as a measure of the overall happiness and well being of the country's population.

The Gross National Happiness Index is a single number index consists from 33 indicators categorized under nine domains: Psychological wellbeing, education, health, cultural differences, Good Governance, community life, time use, environmental diversification and standards of living. (UN, 2015, p. 20)

All domains are weighted equally or at 1/9: Each of the 33 variables is tested through one or more question in the personal interview during the surveys.

The index makes the analysis of the nation's wellbeing with each person's improvement in each indicator. It also provides policymakers how policies may be designed and adjusted to enhance and improve actions for the weaker scoring results of the survey in order to improve overall happiness level.

The Gross National Happiness ranges in value from 0 to 1 . A higher number reflects greater happiness and lower number reflects low levels of happiness. (Karma et al., 2012, p. 48)

c) The United Nations World Happiness Report:

The world Happiness Report calculates the average happiness in a country according to the following elements: GDP (Gross Domestic product) per capita, social improvement, healthy life expectancy, liberty of choices, and corruption. First Report was published in 2012. The report also ranks countries by changes in happiness.

The Report uses Gallup World Poll (GWP). The Report asks people to think of a scale from 0 to 10, 10 represent the happiest life and o represent the unhappiest life. They are then asked to rate their own feeling about their lives on that scale from 0 to 10 . This survey questions are from representative samples from the country to determine the happiness level during the country.

d) Surveys: 
There are many of surveys evolved and used as sources to construct an international rank of happiness. One of the most important surveys is the world value survey.

It is an international survey made by social scientists who study many variables affecting happiness and the impacts of these variables on social life and political life. The survey started in 1981 and involved about 100 countries which consider about $90 \%$ of the world's population, using a unified questionnaire that may have some modifications according to differences between countries in language and cultures.

There are three categories of variables related to happiness in the world value survey: happiness, life satisfaction and subjective well being

Subjective well being $(\mathrm{SWB})=$ life satisfaction $-2.5 *$ happiness

If $100 \%$ of people were very happy, a country would get score of 7.5 which is the highest score. If happiness and life satisfaction was balanced, the country's score is zero. If all of the people were not at all happy, the country would get a score of -9. (Dezhu ye, et al., 2014, p. 528)

\subsection{Measurement Problems}

According to many happiness surveys, like World Value survey which ask questions such as (how do you feel about your life) with responses solicited on a numerical scale to express life satisfaction with as (very happy), (moderately happy), (happy) or (unhappy)

One problem with such open questions is that they leave the meaning of happiness up to the respondent, who may have a different meaning of it than the researcher has. (White, 2014, p. 8\&9)

Another problem with survey based subjective measurements is that people might choose to under or over report some of the issues according to their psychological status during the survey. (Daga, 2014, p. 43)

Also, people's answers to survey questions in different languages and in different cultures sometimes didn't mean the same meaning.

Finally, happiness is a qualitative concept that cannot be translated easily into quantitative questions. So surveys suffer to some degree from reliable and precision results.

\section{Literature Review}

Leonardo Becchetti, Riccardo Massari \& Paolo Naticchioni (2011) this paper investigated the impacts of some variables that affect the levels of happiness and tried to explore changes of happiness inequality by determine the main reasons of the increase in happiness inequality in Germany during the period (1991-2007).

This paper used RIF regressions to investigate the main factors affecting happiness levels and their impacts on happiness inequality.

This paper found that happiness inequality has increased mainly due to employment status and labour market environment also the demographic factor (the increase in the middle age population share) has a negative impact on happiness inequality. On the other hand increase the share of educated people has a negative effect on happiness inequality.

Also, the study found that the increase in income inequality cannot be considered as the only factor of the increase in happiness inequality as there are other factors affecting happiness inequality in Germany.

Jidong Yang \& Yiran Zhang (2015), this paper investigates the determinants of the happiness inequality in China and illustrate the main factors contribute to its enlargement after 2009.

This paper used the RIF regression method to analyse the main reasons of happiness inequality in China.

This paper concluded that happiness inequality can be reduced by an increase in people's income and an increase in income inequality can significantly increase happiness inequality. Improve education and enhancing employment can play an important role in reducing happiness inequality.

An increase in the population share of people who own house also has a happiness inequality reducing impact. Also, Singlehood and increase the population share of middle age people has a negative impact on happiness inequality.

Yoko Niimi (2016) this paper examines the main factor affecting happiness inequality in Japan. This paper used RIF regressions (Recentered Influence function regression).

This paper found that income has a negative impact on happiness inequality. Also, the paper concludes that the insecurity of people about their jobs and life after retirement has significantly enlarging the happiness inequality. 
In our study we will analysis the status of happiness inequality in Egypt and how does it change over time also, we will explore the main factors affecting happiness inequality in Egypt.

In order to investigate the impacts of several variables like: age, educational level, gender, marital status and health on happiness inequality we will use RIF regression (Recentered Influence Function regression) through STAT program and data will be collected from World Value Survey (3 waves: 2001, 2008 and 2012).

\subsection{Happiness Inequality in the World}

Happiness inequality means how much individuals in a country differ in their enjoyment of life. Happiness inequality measures the degree to which people in a country differ in their self reported happiness levels or subjective well being. Happiness inequality usually measured as the standard deviation of happiness.

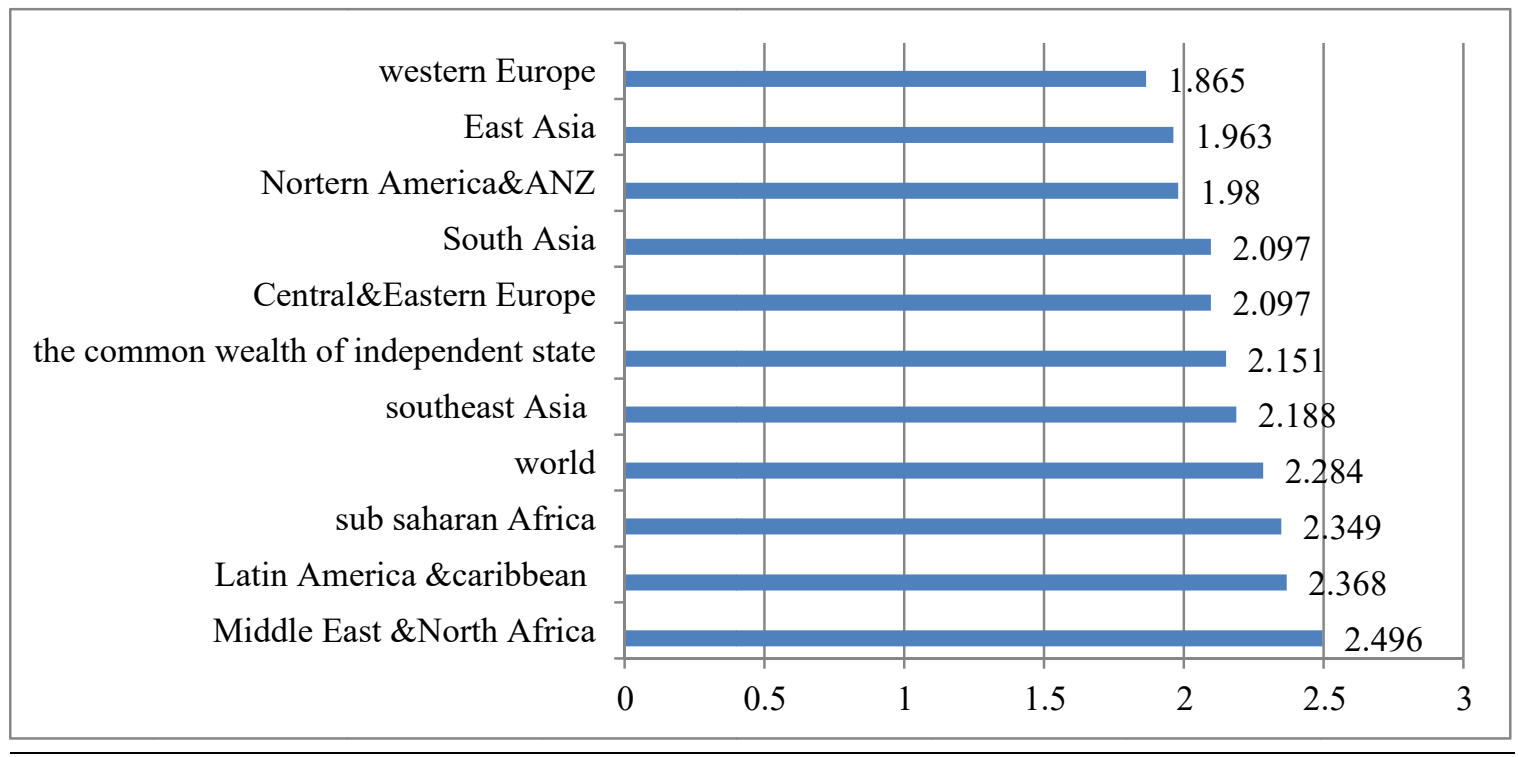

Figure 1. Happiness inequality by global regions (2014-2016)

Source: world Happiness Report 2017, p. 14

When we look at happiness inequality all over the world. we can find that happiness inequality is lowest in Western Europe (1.865) and East Asia (1.963). And highest in Latin America (2.368) and Middle East and North Africa (2.496).

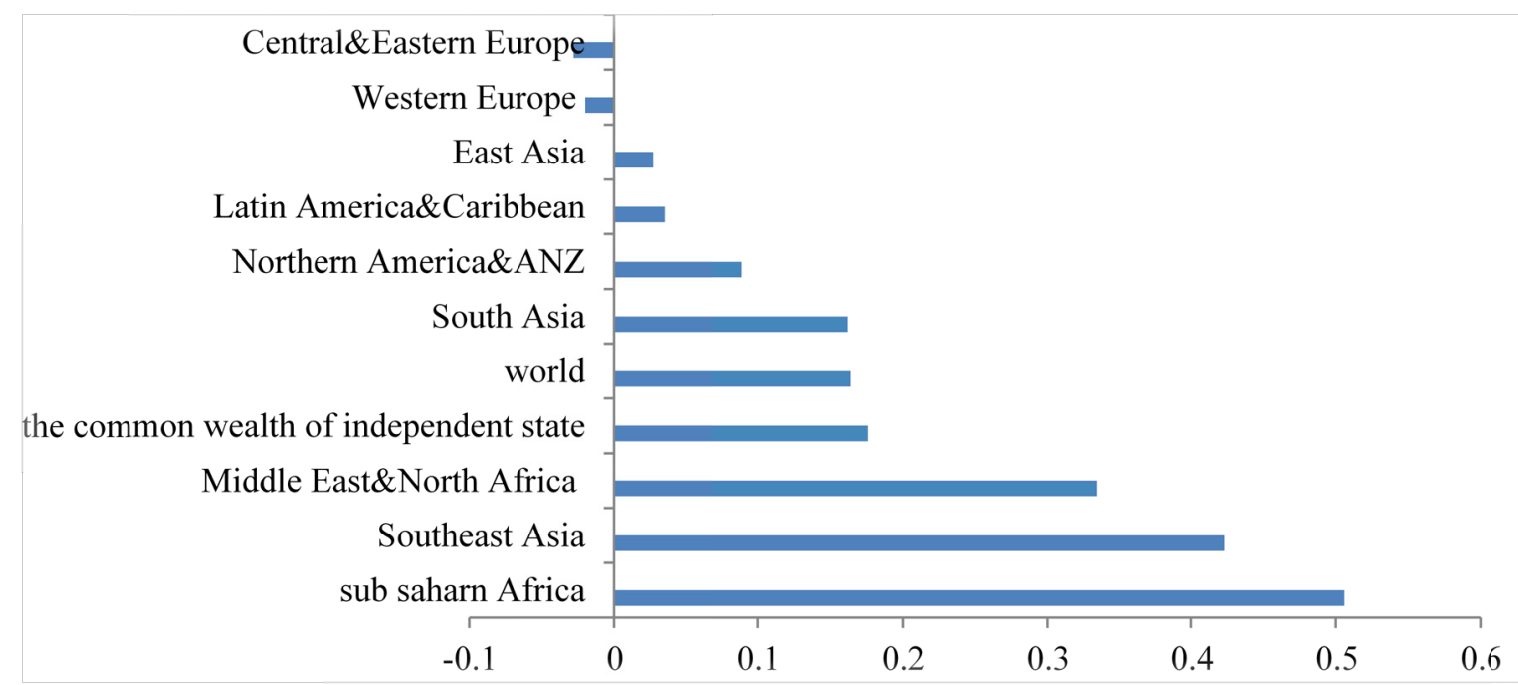

Figure 2. Changes in the inequality of happiness by Region From 2005- 2011 to 2014-2016

Source: calculated by the Author, Data from world happiness Report 2016 \& 2017

From 2005- 2011 to 2014- 2016 happiness inequality has grown significantly from the world as a whole (0.164) 
and for eight of the ten global regions (the exceptions being western Europe and central \& Eastern Europe).

\subsection{Happiness Inequality in Egypt}

According to the world happiness report 2017 Egypt ranked 104 out of 155 countries in happiness index.

Compared to the last year's report Egypt ranks 120 out of 157 countries included in the world happiness report for the year 2016.

But this change is only relative; the overall standard of happiness has dropped worldwide.

Table 1. Happiness in Egypt

\begin{tabular}{ccc}
\hline World happiness Report & Rank & score \\
\hline 2017 & 104 & 4.735 \\
2016 & 120 & 4.362 \\
2015 & 135 & 4.194 \\
2013 & 130 & 4.273 \\
\hline
\end{tabular}

Source: World Happiness Reports, different issues.

Egypt's happiness score in 2017 was 4.735. The average value for Egypt during the period (2013-2017) was 4.39 with a minimum of 4.19 in 2015 and a maximum 4.74 in 2017.

According to the world value survey, Egypt was included in three waves of this survey; wave four for the year 2001, wave five for the year 2008 and wave six for the year 2012. In order to collect data about happiness in these three waves the following standard question is asked to all people included in the sample: Taking all things together, would you say are: very happy, Quite Happy, not very happy, not Happy at all

In 2001, the sample size for Egypt was 3000, $71.3 \%$ of respondents were Quite happy followed by $18.1 \%$ were very happy, only $8.8 \%$ were not very happy and $1.6 \%$ were not at all happy.

In 2008, sample size for Egypt was 3051, 73.5\% of respondents were quite happy followed by $14.8 \%$ were very happy, only $2 \%$ were not very happy and $0 \%$ were not at all happy.

In 2012, sample size for Egypt was only $1523,44.0 \%$ of respondents were not happy at all followed by $30.1 \%$ were not very happy, only $20.7 \%$ were quite happy and $5.3 \%$ were very happy.

The year 2012 witnessed the largest increase in the not at all happy category (reached $44 \%$ in 2012 from 1.6\% in 2001 ) and the highest increase in the not very happy category (this category has been increasing gradually from 2001 till $2012,8.8 \%, 14.8 \%$ and $30.1 \%$ respectively). With a great decline in the quite happy category.

This indicates that more than half of the quite happy respondents were shifted to a lower level of happiness compared to 2001. In 2012 people in the highest level of happiness in the very happy category dropped from $18 \%$ in 2001 to 5.3\%. Keep in mind the political and economic changes happened after the revolution of January 25.

According to world happiness report 2016 the happiness inequality in Egypt measured as the standard deviation of happiness was 2.249 and Egypt ranked 114 out of 157 countries included in this report. Happiness inequality in Egypt increased during the period from (2005-2011) to (2012-2015) by 0.035 .

\subsection{Determinants of Happiness Inequality}

Generally; happiness is found to be higher among: female, married people, the highly educated, the healthy, those with high income, the young and the old because it is $U$ shaped in age and the self employed.

And low among: Newly divorced and separated people, adults in their mid to late 40 s, the disabled and the unemployed, immigrants and minorities, those in poor health. (Blanchflower, 2007, p. 3)

There are many factors that affect happiness inequality:

- Income: increase in average income lead to a decrease in happiness inequality, while the increase in income inequality cannot be considered as the only factors affecting the happiness inequality. (Bacchetti et al., 2014, p. 430)

- Education: increased educational level has an important role in reducing happiness inequality as educated people always reported themselves in high levels of happiness. (Owen \& Phillips, 2013, p. 4)

- Labor market environment: changes in labor market conditions (unemployment and employment rate) play an important role on happiness inequality. The increase in unemployment rate and the decrease in 
employment rate increase the happiness inequality. The more the employment rates and the better labor market condition the more the happiness level. But we must take into our consideration the quality of job (Becchetti, 2010, p. 4)

- Demographic factors: the relationship between happiness and age often referred to as U shape. The relationship between happiness and age called (U shape theory). Happiness declines with age for about two decades from early adulthood up till the middle age years. And then turns upward and increase with age. The shape of the U curve differs from country to country. (Graham \& Pozuelo, 2016, p. 2)

- Geographical factors (urban vs rural): there are two points of view about who is happier who living in urban or rural areas. The first point of view sees that happiness is more in Urban than in rural areas. As poverty and low income that deprives people from having their basic needs is the main factor that would lead to rural unhappiness.

The second point of view sees that happiness has been lowest in the nation's largest cities and has been at its highest levels in small rural areas. That is due to several issues of city life that are likely to make people less happy like traffic, noise, crowds, and higher costs of living. So, who living in rural areas are happier from this point of view.

\subsection{The Relationship Between Happiness Inequality and Income Inequality}

Richard Easterlin was the first modern Economist who investigate the relationship between happiness and income. He found that there was an insignificant relationship between per capita income and happiness; he concluded that increasing income of all will not increase the happiness levels, in which is called the happiness diminishing returns theory. Which mean that marginal happiness is decreasing with absolute income. (Easterin et al., 2011, p. 2)

Several studies tried to investigate the relationship between income inequality and happiness and illustrate the reasons for this relationship.

Some studies have found no significant relationship, either positive or negative between income inequality and happiness. Like (Stevenson, Wolfers, 2008). This paper explores the relationship between changes in happiness and income overtime within countries. This paper concludes that economic growth increase happiness levels. The study is also concluded that limited or no impact of income inequality on happiness levels.

Also (Berg \& Veenhoven, 2010) found no statistically significant relationship between income inequality and happiness by using cross sectional data from 119 different countries.

While other studies found negative relationship between income inequality and happiness. Like Alesina, Di tella \& Mac culloch (2004) who investigate the impact of income inequality on happiness and also compare between European countries and North American. They found a negative relationship between income inequality and happiness.

Also Oishi, Kesebir \& Diener (2011) explores the relationship between income inequality and happiness during the period of 37 years in the United States. The results of their study show a negative relationship between happiness and income inequality.

Now, the question Is Happiness affect income inequality?. Satya Paul (2013), investigates the impact of happiness on income inequality by exploring the causality relationship between happiness and income inequality based on the panel data from the first five waves (2001-2005) of household income and labor Dynamics in Australia survey.

The paper found causality relationship between happiness and income inequality. They found that happiness has a positive impact on income and contributes to the reduction of inequality in direct and indirect way. Directly through enhance work efficiency and indirectly through its effect on the allocation of time for paid work.

\subsection{The Relationship Between Happiness Inequality and Employment}

The relationship between unemployment and happiness comes from two directions. First, Happiness is generally lower for the unemployed and among people with high levels of past unemployment. It was found that compared to other variables affecting happiness, unemployment has been considered to have the most impacts for life satisfaction and happiness level. (Scheve, 2016, p. 5)

We should also take into consideration the quality of job. As poor quality jobs are more likely to be related with health problems (whether physically or philological). So, losing a poor quality job doesn't affect an individual's satisfaction and happiness the same as losing a good quality one. 
On the other side, high happiness levels can benefit the workers in a country and increase their productivity and also encourage those who are unemployed to work and produce. So, some jobs can be directly affected by levels of happiness.

There are several studies investigate the relationship between employment and happiness.

(Blanchflower et al., 2014), this paper found that unemployment and inflation lower happiness levels. The authors used a large European Dataset from the period (1975 to 2013), to estimate happiness patterns in which an life satisfaction and happiness is affected by unemployment and inflation rate.

Authors found that both higher unemployment and higher inflation lower happiness levels and unemployment decrease happiness level more than inflation.

The authors explore the relationship between happiness, unemployment and inflation using the misery ratio. Using OLS the authors found that a one percentage point increase in the unemployment rate lowers happiness levels by more than five times as much as one percentage point increase in the inflation rate.

(Streimikiene \& Grundey, 2009), this paper investigate the role of work in wellbeing, life satisfaction and happiness. This paper analyses the latest studies illustrate the impact of work on life satisfaction and happiness.

This paper found that money is the main incentive of work, but money themselves and without other factors do not enhance happiness. Also the results illustrate the importance of the quality of working life rather than just having a job.

(Ohtake, 2012), the authors in this paper tried to answer the question whether unemployed people are unhappier than employed people?. The main result in this study that when the income level and other factors are held constant, unemployment reduces people's happiness.

The data used for the analysis of the relationship between happiness and unemployment are collected from the Questionnaire survey on lifestyle and society 2002.

(Dockery, 2003) this paper analysis the main elements that influence Australians' level of happiness with an concentration on the role of labor market condition. This paper used data from two surveys.

The results concluded the importance of the quality of job on happiness levels, rather than just having a job. The results also found that unemployed young people are less happy than those in study or employment. And those who unemployed for a long time have lower levels of happiness.

Also, an important finding is the importance of the quality of job on happiness levels. They found that being employed in a bad job has greater impacts on happiness levels than unemployment.

\subsection{The Relationship between Happiness Inequality and Education}

Recent studies have found a negative relationship between education and happiness. People with higher education are more likely to be happier than their less educated people. So increase educational level will increase happiness level. (Nikolaev, 2015, p. 1)

There are both direct and indirect effects of education on happiness. the direct effects of education on happiness come from "self confidence" or "self estimation" effect from acquiring knowledge through education degrees. While the indirect effect of education on happiness through increasing income and acquiring a good job.

Studies found that individuals with a high degree of education have higher level of income and have a probability of being employed so, report higher levels of happiness. (Cunado \& Fernando de Gracia, 2011, p. 190)

\subsection{Gender Differences in Happiness}

According to many surveys have been conducted in many countries; in average woman reported as having higher life satisfaction than the average man. Women report higher levels of happiness in life compared to men.

(Nordenmark, 2018) this study compare the importance of job satisfaction and satisfaction with family between women and men. This paper used comparative data from the international social survey program 2012. Results found that in general the level of satisfaction with family life more important to the level of happiness than the level of job satisfaction.

Also, the study found that the level of satisfaction with family life are less important to men's level of happiness than women.

Inglehart (2002) this paper used data from the world value survey for over than 60 countries to investigate the relationship between gender and happiness. The paper found that gender differences in happiness levels were 
affected mainly by age, they found that young women (18-44) are happier than young men, middle aged (45-54) women and men do not differ in terms of happiness. But older (55+) women are less happy than older men.

(Garham \& Challopadhyay, 2012), this paper investigate gender differences in reported well being around the world both between countries and within countries with comparing age, income and education groups.

The main finding is that women are happier than men worldwide, with a few exceptions in low income countries. Also, the standard deviation of happiness level for women is lower than that of men which mean that happiness inequality for women is lower than happiness inequality for men. They found that the gap between male and female happiness is also greater in countries with higher levels of developments.

The gap between male and female happiness is greater (women having higher level than men) in older, more educated people and in urban areas. Also, the paper found that the gap between women and men's happiness is greater where gender rights are more equal.

Findings about martial status, that while married people have higher happiness levels than single and separated people in high income countries and in urban areas, married people have lower than the average level in low income countries (like in Sub Saharan Africa area).

Also, Married women are happier than married men in high income countries, but there are no significant differences in happiness level for married women and men in the low income countries. The happiness gap between female and male is higher for those with more educational level.

\subsection{Happiness Inequality in Egypt}

Using the World Value Survey (3 waves: 2001, 2008 and 2012) database, we explore the main factors affecting happiness inequality in Egypt. We try to answer the following two questions:

a) What is the status of happiness inequality in Egypt and how does it change over time?

b) What are the main factors that affecting happiness inequality in Egypt?

We analyse the main factors affecting happiness inequality using RIF regression (Recentered influence function) by using STAT program.

RIF Regression mainly developed by Fripo et al. (2009). The RIF is defined as RIF(y,fy)=V(F) + IF (y; Fy).

Using the law of iterative expectations, the relationship between the statistics $V(F)$ and the explanatory variable $\mathrm{X}$ as follows

$$
\begin{aligned}
& V(F y)=\{\operatorname{RIF}(y, f y) d \text { fy } \\
& V(F y)=\{E[R I F(y, F y) I X=x] d \text { fx }(X) \\
& \operatorname{RIF}(y: v, f)=v(F)+\{I F(y ; v) \\
& \quad d \Delta y(y)=V(F)+\text { If }(y ; v)
\end{aligned}
$$

Regression based estimator, $\beta=$

$\mathrm{E}[\mathrm{RIF}(\mathrm{y} ; \mathrm{v}, \mathrm{f}) \mathrm{IX}=\mathrm{x}]=\alpha+\mathrm{X} \beta$

Mean of the Recentered Influence function will be

$\{\operatorname{RIF}(y ; v) \cdot d f(y)=\{v(f)+\operatorname{IF}(y ; v) \cdot d f(y)=v(f)$

The variance of RIF (y;v) equal

$\left\{[R I F(y ; v)-v(f)]^{2} \cdot \operatorname{df}(y)\right.$

$=\left(\operatorname{IF}(\mathrm{y} ; \mathrm{v})^{2} \cdot \mathrm{d} \mathrm{f}(\mathrm{y})=\mathrm{AV}(\mathrm{V}, \mathrm{f})\right.$

RIF (Happiness inequality)

$=\alpha+\beta 1$ Age $+\beta 2$ Sex $+\beta 3$ education level $+\beta 4$ Employment status $+\beta 5$ Income $+\beta 6$ status of health $+\varepsilon$

The explained variable is happiness inequality. The explanatory variables include age, gender, education, Income, employment status, martial status and health status.

\begin{tabular}{|c|c|c|c|c|c|c|c|c|c|}
\hline Year & Not & No & Don't & Very & Quite & $\mathrm{N}$ & Mean & & Std Dou \\
\hline
\end{tabular}

3.9 Distribution of Happiness in Egypt (2001- 2012)

Table 2. Feeling of happiness in Egypt Feeling of Happiness 


\begin{tabular}{cccccccccc}
\hline & asked & answer & know & happy & happy & & & & (SD) \\
\hline 2001 & 0.2 & 18.07 & 71.33 & 8.83 & 1.57 & 3000 & 1.93 & .345 & .588 \\
2008 & 0.03 & 9.8 & 74.4 & 13.93 & 1.84 & 3051 & 2.08 & .310 & .557 \\
2012 & 5.84 & 23.83 & 28.76 & 41.56 & 5.84 & 1523 & 3.06 & .885 & .941 \\
\hline
\end{tabular}

Source: World value survey 3 waves

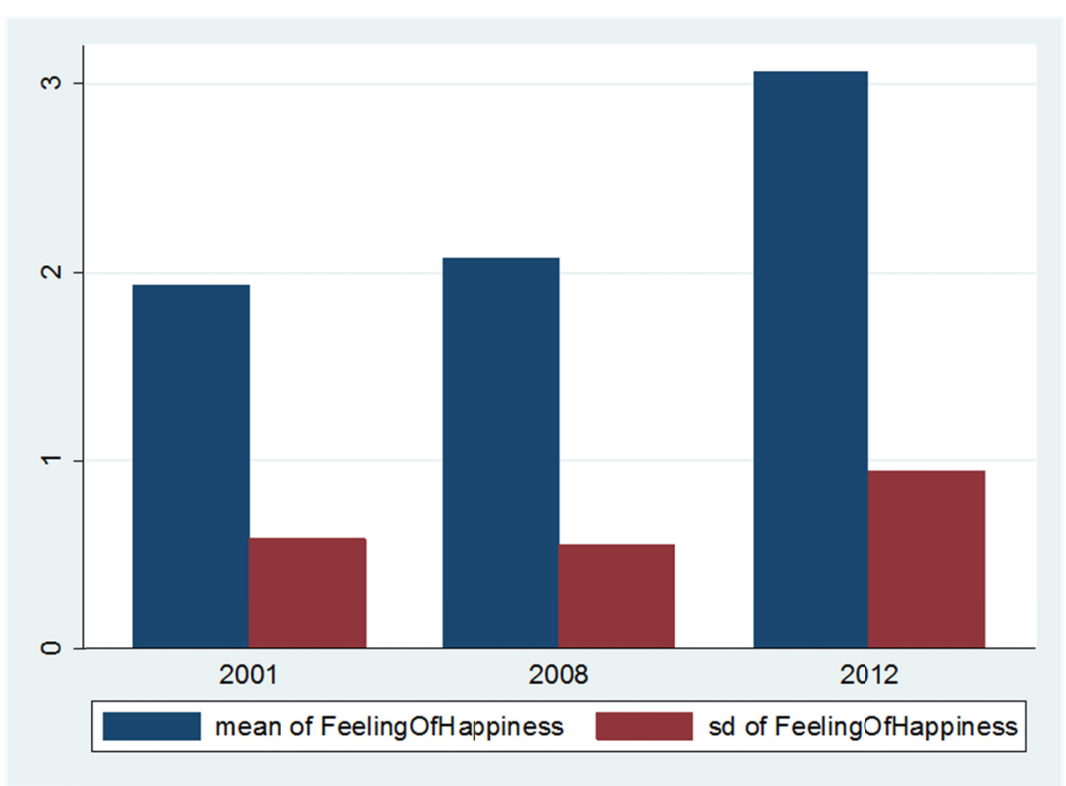

Figure 3. Feeling of happiness in Egypt

Table 1 describes the happiness distribution in Egypt (feeling of happiness). While the mean value of happiness increases from 1.93 in 2001 to 3.06 in 2012.

Also the variance of happiness also shows an upward trend. The proportion of (very happy) rapidly rises from $8.83 \%$ in 2001 to $41.56 \%$ in 2012 .

Also the standard deviation increased from 0.588 in 2001 to 0.941 in 2012 which mean increasing happiness inequality in Egypt.

Table 2. International comparison of happiness inequality 2012

\begin{tabular}{cccccccc}
\hline & world & Egypt & U.S & India & Brazil & china & Singapore \\
\hline Mean & 3.141 & 3.06 & 3.263 & 3.1 & 3.260 & 3.06 & 3.305 \\
S.D & 0.743 & 0.941 & 0.641 & 0.828 & 0.626 & 0.585 & 0.614 \\
\hline
\end{tabular}

Source: World value survey

By analysing the data from world value survey, we can find that the level of Egypt happiness is, on average, lower than the world and many other countries. But the Egypt happiness inequality is higher than the world average and many other countries.

Table 2 shows that Egypt suffer from happiness inequality problem. So we will analyse the main factors affecting happiness inequality in Egypt using RIF regression according to data from world value survey (3 waves: 2001, 2008 \& 2012).

\section{Results}

From RIF regression we found the following results:

- For income, an increase in income has a negative impact on happiness inequality.

Some studies like (Alesina, Di tella \& Culloch, 2004) found a negative relationship between income inequality and happiness when they made a comparison between European and North American countries.

While other studies like (Berg \& veenhoven, 2010) found no statistically significant relationship between income inequality and happiness by using cross sectional data from 119 different countries. 
- $\quad$ For educational level, an increase in educational level reduces happiness inequality. This result is similar to result of Yang et al. (2015) when investigate happiness inequality in china. They found that an increase in educational level can reduce happiness inequality.

Also (Becchetti et al., 2011) that conclude that education has a direct effect in reducing happiness inequality and higher education has an important effect on happiness. people fulfil higher education has a probability of having high happiness level

-For employment status, being employed reduce happiness inequality.

The same result as (Blanchflower et al., 2014) that conclude that higher unemployment lower wellbeing and happiness levels and unemployment has greater impact on happiness than inflation.

Also (Streimikiene \& Gundey, 2009) found that unemployed people are unhappier than employed people and also show the importance of the quality of working environment on happiness rather than just having a job.

- $\quad$ For gender, female have higher life satisfaction than male. So, increase in female's proportion can reduce happiness inequality.

Same result as (Graham \& Challopadhyay, 2012) who found that women are happier than men worldwide with a few exceptions in low income countries.

But this result opposite to (Stevenson \& Wolfers, 2009) that found that women's happiness has declined both absolutely and relative to men. They explain the difference in female and male's happiness that female tend to focus on personal \& domestic problems while men concern more with matters outside of the home like work.

- $\quad$ For age, older people are happier than young people. This is because the middle age people feel more life pressures in Egypt.

(Blanchflower \& Oswald, 2008) found that the relationship between happiness and age is followed U shaped theory. Happiness declines with age for about 2 decades from early adulthood up till the middle age years and then turns upward and increase with age.

Other studies like (Inglephart et al., 2008) and (Deaton, 2007) confirm the U shape happiness theory for the relationship between age and happiness.

These studies explain the reasons for the $U$ shape in two issues first younger individual have higher expectations than old people that are not met. Second, older individuals learn to adapt to their strengths and weaknesses and thus have more realistic about their life and expectations.

- $\quad$ For Martial status, Marriage and having family associated with higher levels of happiness.

Studies like (Nordenmark, 2018), (Zhenzhu Wu, 2014) and (Navaitis, 2016) have already shown the relationship between marriage and happiness, the married people usually reporting significantly higher level of happiness than those who are single, separated, divorced or widowed.

Also studies show that the level of satisfaction with family appears to be one of the most important factor to the general level of happiness.

- For health status, Results show that individuals who report themselves to be in good health have a probability of being at greater levels of happiness.

Studies show that health affect happiness and happiness affect health. People who are happy and satisfied with their lives are usually healthier than people who are not happy. So happiness leads to better health. Also, good health is lead to higher happiness levels. It is a causality relationship between happiness and health.

(Gerstenbluth \& Rossi, 2013) conclude that people who report themselves to be in good health have a probability of being at the highest level of happiness between 13 and 20 percentage points higher than individuals who report themselves as in poor health.

Also, (Graham, 2008) conclude that health and happiness are related to each other. The positive relationship between happiness and health tends to be stronger for Psychological health than for Physical health. Meanwhile, serious illness or disabilities have strong and negative effects on happiness.

Graham also conclude that even countries with poor health standards healthier people are happier as health affect happiness levels.

\section{Conclusion}

This paper utilizes the RIF regression method (Using STAT program) to analyse the happiness inequality in 
Egypt and determine what are the main factors affecting happiness inequality in Egypt.

The main findings that Egypt suffers from happiness inequality and happiness inequality in Egypt has been enlarged during the period from 2001 to 2012.

Also, we found that the increase in income inequality is not the only factor that increases happiness inequality. There are several factors that influence happiness inequality such as: age, gender, educational level, employment and status of health.

Improving educational level and increasing employment rate (with good jobs) play an important role in reducing happiness inequality.

An increase in the population share of middle age is affected happiness and increase happiness inequality. As younger people is unhappier compared to old people. This is due to time and work pressure effects.

With regard to gender, females report greater level of happiness compared to males.

Also, we found that who married and having family have higher level of happiness than single. Also results show that people who report themselves to be in good health have greater levels of happiness.

\section{References}

Alesina, A., Di tella, R., \& Macculloch. (2004). Inequality and happiness: Are Europeans and Americans different? Journal of Public Economics, 2009-2042.

Andrew, J. (2009). Happiness and productivity. Oswald university of Warwick and IZA, Eugenio proto university of warwick Daniel.

Becchetti, L., Massari, R., \& Naticchioni, P. (2010). Why has happiness inequality increased. ECINEQ working paper, 177.

Becchetti, L., Massari, R., \& Naticchioni, P. (2011). The drivers of happiness inequality suggestions for promoting social cohesion. IZA Discussion paper, (7153), 1-34.

Berg, M., \& Veenhoven, R. (2010). Income inequality and happiness in 119 nations. Social policy\& happiness in Europe, Chapter 11, 174-194.

Blanchflower, D. (2007). Is unemployment more costly than inflation. Nber working paper series, National Bureau of Economic Research, Massachusetts Avenue Cambridge.

Blanchflower, D. et al. (2014). The happiness trade off between unemployment and inflation. Journal of Money credit and Banking.

Clark, A, \& Senik, C. (2015). Happiness and Economic growth: Lessons from developing countries. Oxford Scholarship.

Cunado, J., \& Fernando de Gracia, (2011). Does education affect happiness? Evidence for Spain. Social Indicators Research, 108(1), 185-196.

Daga, G. (2014). Towards a new development paradigm: Critical analysis of gross national happiness (Master thesis). Jindal School of Government and Public Policy.

Deaton. (2007). Income, aging, health and wellbeing around the world: evidence from the Gallup world pall. NBER working paper no.13317.

Delhey, J., \& Kohler, U. (2011). Is happiness inequality immune to income inequality? New evidence through instrument effect corrected standard deviation. Social science Research, 40(2011), 742-756, doi:10.1016/j.ssresearch.2010.12.004

Dezhu Ye et al. (2014). Culture and Happiness. Springer Publishing, August 2014.

Dockery. (2003). Happiness, life satisfaction and the role of work: Evidence from two Australian survey, full employment Imperative no77.

Easterin, R. et al. (2011). The happiness income paradox revisted. University of Southern California, paper no 5799

Fripo et al. (2009). Unconditional Quantile Regression. Econometrica, 77(3), 953-973.

Garham, C., \& Challopadhyay, S. (2012). Gender and well being around the world: Some insights from the Economics of happiness. Human capital and economic opportunity working group, Economic research center, working paper no. 010 
Gerstenbluth, \& Rossi. (2013). Are healthier people happier? Evidence from chile and Uruguay. Development in Practice, 23(2).

Graham C., \& Ruiz Pozuelo, J. (2016). Happiness, stress and Age: how the U curve varies across people and places. Journal of Population Economics, 30th Anniversary issue

Graham. (2008). Happiness and health: Lessons and questions for public policy. Health Affairs, 27(1).

Inglehart et al. (2008). Development freedom and rosing happiness - a global perspective (1981-2007). Perspectives on Psychological Science, 3, 264-285.

Inglehart. (2002). Gender, aging and subjective well being. International Journal of Comparative Sociology, 43(3-5), 391-408.

Karma, U. R. A. et al. (2012). A short guide to gross national happiness index. The Centre for Bhutan Studies.

Navaitis, G. (2016). The marital status and the happiness. Proceedings of the International Conference, 1 , 458-468.

Niimi, Y. (2016). What affects happiness inequality? Evidence from Japan. Journal of Happiness Studies, 1-23

Nikolaev B. (2015). Education and happiness: An alternative hypothesis (p. 1). Department of Economics, Oxford College of Emory University.

Nordenmark, M. (2018). The importance of job and family satisfaction for happiness among women and men in different gender regimes. Societies, $8(1)$.

Ohtake, F. (2012). Unemployment and happiness. Japan labour Review Journal.

Oishi, Kesebir, \& Diener. (2011). Income, inequality and happiness psychological science, 1095-1100

Owen, A., \& Phillips, A. (2013). Education, income and the distribution of happiness. Munich Personal Repec Archive, working paper no. 49387.

Paul S. (2013). Reserving the Cauality: Does happiness reduce income inequality. University of Western Sydney.

Scheve, C. (2016). The Emotional Timeline of Unemployment: Anticipation, Reaction and Adaption. Journal of Happiness Studies.

Singh, T. (2014). A study on gross national happiness: Catalyst of developing nation. International Journal of Commerce, Business \& Management.

Stevenson, \& Wolfers. (2009). The paradox of declining female happiness. National Bureau of Economic Research, no. 14969.

Stevenson, B., \& Wolfers, J. (2008). Economic growth and subjective well being: Reassessing the Easterlin Paradox. NBER working paper no.14282.

Streimikiene, D., \& Grundey, D. (2009). Life satisfaction and happiness - The factors in work performance. Economics \& Sociology, 2(1), 9-26. Guest Editional.

U.N. World happiness Reports, different issues.

White, M. (2014). The problems with measuring and using happiness for policy purposes. Mercatus working paper, George Mason University.

Wu, Z. Z. (2014). Family is the most influential factor on happiness in high school students. Health, 6(5), 336-341.

Yang, J., Kailiu, \& Zhang, Y. (2015). Happiness inequality in China. Munich personal Repec Archive, no. 6623.

\section{Appendix}

Factors influencing happiness:

\begin{tabular}{cccccccc}
\hline & \multicolumn{3}{c}{ Year } \\
\cline { 2 - 7 } & & \multicolumn{2}{c}{2001} & \multicolumn{2}{c}{2008} & \multicolumn{2}{c}{2012} \\
\cline { 2 - 7 } & & Count & Percent \% & Count & Percent \% & Count & Percent \% \\
\hline \multirow{3}{*}{ State Of Health } & 1 & 591 & $19.7 \%$ & 471 & $15.4 \%$ & 241 & $15.8 \%$ \\
& 2 & 1435 & $47.8 \%$ & 1578 & $51.7 \%$ & 638 & $41.9 \%$ \\
& 3 & 724 & $24.1 \%$ & 766 & $25.1 \%$ & 392 & $25.7 \%$ \\
\hline
\end{tabular}




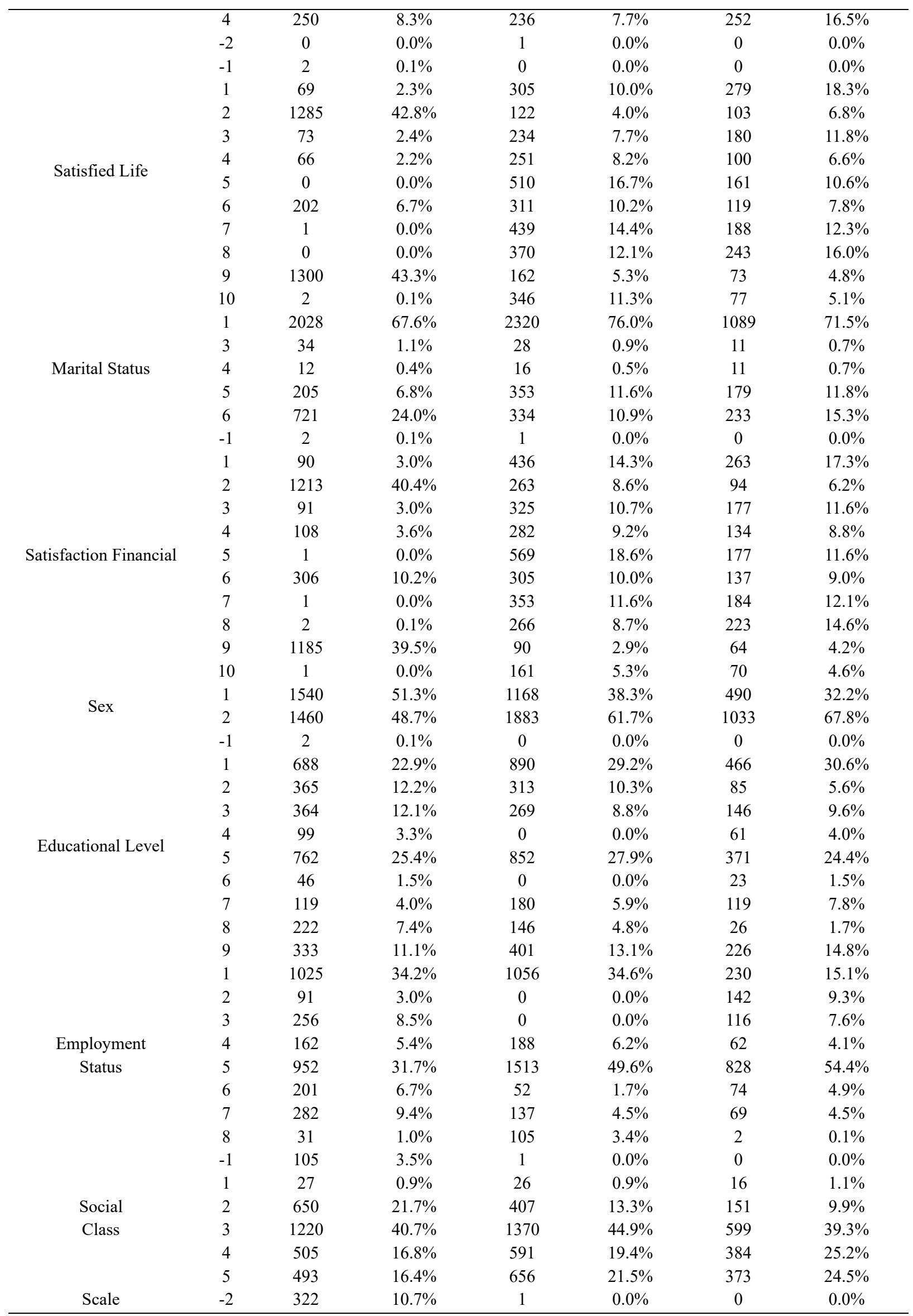




\begin{tabular}{|c|c|c|c|c|c|c|c|}
\hline \multirow[t]{15}{*}{ Of Income } & -1 & 0 & $0.0 \%$ & 3 & $0.1 \%$ & 0 & $0.0 \%$ \\
\hline & 1 & 153 & $5.1 \%$ & 408 & $13.4 \%$ & 175 & $11.5 \%$ \\
\hline & 2 & 201 & $6.7 \%$ & 440 & $14.4 \%$ & 147 & $9.7 \%$ \\
\hline & 3 & 247 & $8.2 \%$ & 500 & $16.4 \%$ & 229 & $15.0 \%$ \\
\hline & 4 & 333 & $11.1 \%$ & 508 & $16.7 \%$ & 274 & $18.0 \%$ \\
\hline & 5 & 285 & $9.5 \%$ & 659 & $21.6 \%$ & 262 & $17.2 \%$ \\
\hline & 6 & 417 & $13.9 \%$ & 245 & $8.0 \%$ & 204 & $13.4 \%$ \\
\hline & 7 & 495 & $16.5 \%$ & 177 & $5.8 \%$ & 146 & $9.6 \%$ \\
\hline & 8 & 252 & $8.4 \%$ & 71 & $2.3 \%$ & 81 & $5.3 \%$ \\
\hline & 9 & 236 & $7.9 \%$ & 22 & $0.7 \%$ & 3 & $0.2 \%$ \\
\hline & 10 & 59 & $2.0 \%$ & 17 & $0.6 \%$ & 2 & $0.1 \%$ \\
\hline & 0 & 872 & $29.1 \%$ & 536 & $17.6 \%$ & 574 & $37.7 \%$ \\
\hline & 1 & 244 & $8.1 \%$ & 303 & $9.9 \%$ & 190 & $12.5 \%$ \\
\hline & 2 & 411 & $13.7 \%$ & 555 & $18.2 \%$ & 330 & $21.7 \%$ \\
\hline & 3 & 531 & $17.7 \%$ & 625 & $20.5 \%$ & 247 & $16.2 \%$ \\
\hline \multirow{6}{*}{ children } & 4 & 362 & $12.1 \%$ & 439 & $14.4 \%$ & 102 & $6.7 \%$ \\
\hline & 5 & 249 & $8.3 \%$ & 271 & $8.9 \%$ & 41 & $2.7 \%$ \\
\hline & 6 & 166 & $5.5 \%$ & 171 & $5.6 \%$ & 24 & $1.6 \%$ \\
\hline & 7 & 85 & $2.8 \%$ & 84 & $2.8 \%$ & 8 & $0.5 \%$ \\
\hline & 8 & 72 & $2.4 \%$ & 67 & $2.2 \%$ & 7 & $0.5 \%$ \\
\hline & 9 & 8 & $0.3 \%$ & 0 & $0.0 \%$ & 0 & $0.0 \%$ \\
\hline
\end{tabular}

Status of health: 1 very good $\quad 2$ Good $\quad 3$ fair 4 poor

Satisfied with life: -2 no answer -1 Don't know 1 Dissatisfied 10 satisfied

Martial status: 1 Married 3 Divorced 4 separated 5 windowed 6 single

Satisfaction with financial: -1 Don't know 1 Dissatisfied 10 satisfied

Sex: 1 male 2 female

Educational level: -1 Don't know 1 no formal education 2 incomplete primary school 3 complete primary school 4 incomplete secondary school/technical/vocational type 5 complete secondary school /technical type 6 incomplete secondary:university preparatory type 7 complete secondary: university preparatory type 8 some university without degree 9 university with degree.

Employment status: 1 full time 2 part time 3 self employed 4 Retired 5 housewife 6 students 7 unemployed 8 others

Social class: -1 Don't know 1 upper class 2 upper middle class 3 lower middle class 4 working class 5 lower class

Scale of income: -2 no answer -1 Don't know 1 low 10 high

\section{Linear Regression}

Coefficients:

\begin{tabular}{|c|c|c|c|c|}
\hline \multirow[b]{2}{*}{ (Intercept) } & \multicolumn{3}{|c|}{ Estimate Std. Error t value } & $\operatorname{Pr}(>|t|)$ \\
\hline & \multicolumn{4}{|c|}{$-1.511 \mathrm{e}+02 \quad 3.718 \mathrm{e}+00-40.654<2 \mathrm{e}-16 * * *$} \\
\hline StateOfHealth & \multicolumn{4}{|c|}{$2.724 \mathrm{e}-01 \quad 9.289 \mathrm{e}-03 \quad 29.320<2 \mathrm{e}-16 * * *$} \\
\hline satisfiedLife & \multicolumn{4}{|c|}{$-4.016 \mathrm{e}-02 \quad 2.756 \mathrm{e}-03-14.576<2 \mathrm{e}-16 * * *$} \\
\hline MaritalStatus & \multicolumn{4}{|c|}{$1.307 \mathrm{e}-02 \quad 4.103 \mathrm{e}-03 \quad 3.1850 .001452 * *$} \\
\hline \multicolumn{5}{|c|}{ SatisfactionFinancial $-1.598 \mathrm{e}-02 \quad 2.887 \mathrm{e}-03 \quad-5.5373 .19 \mathrm{e}-08 * * *$} \\
\hline Employment status & $-5.900 \mathrm{e}-027$ & $7.143 \mathrm{e}-03-8$ & $-8.261<$ & $2 \mathrm{e}-16 * * *$ \\
\hline Sex & $-6.533 \mathrm{e}-02$ & $1.807 \mathrm{e}-02$ & -3.615 & $0.000303 * * *$ \\
\hline Age & $-2.403 e-03$ & $6.027 \mathrm{e}-04$ & -3.987 & $6.76 \mathrm{e}-05 * * *$ \\
\hline ScaleOfIncome & $7.722 \mathrm{e}-03$ & $3.213 \mathrm{e}-03$ & 2.403 & $0.016282 *$ \\
\hline
\end{tabular}


children

$-2.446 \mathrm{e}-02 \quad 4.534 \mathrm{e}-03 \quad-5.3957 .05 \mathrm{e}-08 * * *$

Educational level

$$
7.642 \mathrm{e}-02 \quad 1.859 \mathrm{e}-03 \quad 41.097<2 \mathrm{e}-16 * * *
$$

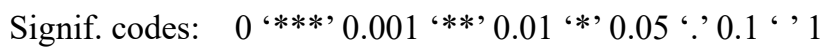

Residual standard error: 0.6443 on 7560 degrees of freedom

Multiple R-squared: 0.3342 , Adjusted R-squared: 0.333

F-statistic: 291.8 on 13 and 7560 DF, p-value: $<2.2 \mathrm{e}-16$

RIF Regression Results:

\begin{tabular}{llll}
\hline & 2001 & 2008 & 2012 \\
\hline Income & & & \\
Low income & 0.493 & 0.352 & 0.241 \\
High income & -0.240 & -0.135 & -0.324 \\
Educational level & & & \\
No formal education & 0.210 & 0.104 & 0.356 \\
Some school education & -0.352 & -0.241 & -0.284 \\
Higher education & -0.582 & -0.454 & -0.692 \\
Employment Status & & & \\
Employment & -0.341 & -0.457 & -0.254 \\
Unemployment & 4.051 & 3.123 & 5.345 \\
Retired & -0.123 & -0.267 & -0.248 \\
sex & -0.0301 & -0.0171 & -0.0209 \\
Age & & & \\
Up to 29 y & -0.264 & -0.158 & -0.342 \\
30- 49 y & 0.542 & 0.483 & 0.642 \\
50 or more & 0.210 & 0.103 & 0.198 \\
Martial status & & & \\
Married & -0.452 & -0.398 & -0.238 \\
single & 0.146 & 0.213 & 0.108 \\
Status of health & & & \\
Good health & -0971 & -0.625 & -0.837 \\
Poor health & 0.325 & 0.231 & 0.382 \\
\hline
\end{tabular}

\section{Copyrights}

Copyright for this article is retained by the author(s), with first publication rights granted to the journal.

This is an open-access article distributed under the terms and conditions of the Creative Commons Attribution license (http://creativecommons.org/licenses/by/4.0/). 